\title{
0 Crítico e a Função da Crítica Diante da Cena Contemporânea
}

\author{
Clóvis Domingos dos Santos* \\ Universidade Federal de Ouro Preto - UFOP, Ouro Preto, Brasil \\ E-mail: clovpalco@gmail.com \\ Paulo Marcos Cardoso Maciel** \\ Universidade Federal de Ouro Preto - UFOP, Ouro Preto, Brasil \\ E-mail: paulinhomaciel@uol.com.br
}

Resumo

Partindo do princípio de que toda crítica traz consigo um olhar específico sobre o fazer e o pensar o teatro, buscamos identificar e analisar alguns dos principais programas críticos formulados ao longo do século $\mathrm{XX}$ e seus desdobramentos ou interfaces com a produção mais recente. Nossa hipótese é de que o ofício, o objeto e o território do crítico no Brasil vêm-se transformando nos últimos anos em virtude de um cenário distinto vivenciado pelas artes cênicas no país. Nesse sentido, o território expandido da atuação do crítico compreende uma rede de colaboradores em luta pelo teatro e por seu lugar no mundo. Menos que uma superação da crítica moderna ou de seus limites cognitivos, o que vemos hoje é o conflito entre perspectivas resultantes do aumento da complexidade da questão devido à sobrevivência atual de práticas pretéritas.

\section{Palavras-chave}

Crítica teatral brasileira. História. Cena contemporânea.
Abstract

Departing from the principle that all criticism includes a specific perspective about the practice and thought involved in theatre, we sought to identify and analyse some of the main critical trends formed throughout the 20th century with their branches and interfaces in more recent production. Our hypothesis is that the craft, the object and the territory occupied by the critic in Brazil have been undergoing transformations in the last few years because of the distinct scenario experienced by the Scenic Arts in the country. In that sense, the expanded territory for the critic's practice comprehends a network of collaborators, struggling over the meaning of theatre and its role in the world. Instead of overcoming modern criticism or its cognitive limits, what we find today is the conflict between perspectives that resulted from an increase in complexity of the issue, that resulted in turn from the survival, to this day, of past practices.

Keywords

Brazilian Theatre Criticism. History. Contemporary Scene.

\footnotetext{
* Artigo resultante do projeto de pesquisa em andamento intitulado Crítica e Cena Contemporâ-nea, com a supervisão do Prof. Dr. Paulo Marcos Cardoso Maciel. Bolsista PNPD/CAPES no Programa de Pós-Graduação em Artes Cênicas da Universidade Federal de Ouro Preto. Crítico no site Horizonte da Cena (BH/MG).
}

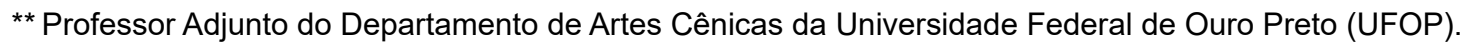


Introdução

O teatro de amanhã não será como o de hoje ou o de ontem e o de anteontem, por uma razão muito simples: é que o teatro, a arte, a história, a crítica, não se repetem, tudo isso vive de um novo que se quer sempre outro que não ele mesmo, que se quer em estado de renovação constante. Nada é mais contrário à arte do que a estabilidade (BORNHEIM, 1983, p. 118).

Neste artigo, nos propomos a refletir sobre a crítica teatral brasileira na atualidade, abordando (do ponto de vista historiográfico e sociológico) as continuidades e rupturas sofridas entre o trabalho dos críticos modernos e contemporâneos, bem como problematizando seus pressupostos ideológicos e suas ferramentas de atuação. Partimos das questões que suscitam a crítica teatral hoje, caminhando depois para um recorte histórico no século $X X$ até desembocar nos aspectos presentes da crítica teatral contemporânea e no modo como tem ocorrido seu diálogo com a cena e com a realidade social de nosso tempo. Nesse percurso, nosso interesse é evidenciar que a crítica continua em plena atividade, conservando funções consideradas mais tradicionais, como mediação e avaliação de espetáculos, e simultaneamente se transmudando e se reinventando a partir de novas modulações e reivindicações estético-sociais.

Para pensar a crítica teatral hoje tornase necessário reconhecer as especificidades do tempo e do espaço em que tem operado seu exercício reflexivo, quais critérios têm balizado os juízos, e mais: que tipos de discurso esses juízos têm produzido. De que modo a crítica teatral tem sido afetada por um contexto marcado pela aceleração e simultaneidade do tempo, pela fragmentação do espaço e diminuição das distâncias, em virtude da propagação das redes, pela multiplicidade das linguagens artísticas em sintonia com as novas demandas políticas e sociais? De que maneira tem sido seu diálogo com a produção e a recepção teatral de seu tempo, caracterizadas, segundo os autores, (FÉRAL, 2015; FERNANDES, 2000, 2010; COHEN, 2004; DESGRANGES, 2003, 2017; PAVIS, 2010; LEHMANN, 2007; SARRAZAC, 2012, 2017) pelo hibridismo e pela polifonia? A partir das novas tendências do teatro contemporâneo, como se daria a reflexão crítica a respeito de fenômenos espetaculares que sempre desafiam os estudos teóricos, exigindo contínuo trabalho de atualização, análise e reinvenção?

Entre as inúmeras tendências que podem ser observadas no horizonte da cena teatral do presente, duas linhas de força têm caracterizado as produções artísticas brasileiras: os processos coletivos de criação e as práticas em campo expandido. Desde os anos 60 , a criação coletiva se faz presente na forma de produção de muitos grupos que buscam democratizar o fazer teatral por meio do questionamento das funções especializadas e hierarquizadas, abolindo, para tanto, os papéis fixos delimitados, sobretudo, pela encenação moderna,${ }^{1}$ centrada na autoria e na autoridade do encenador ou do diretor:

\footnotetext{
Muitas são as razões levantadas para o surgimento da criação coletiva. Tanto os elementos conjunturais da época - marcada pela contracultura, pelo movimento hippie e seu projeto comunitário, pelo ativismo político e libertário acentuado - quanto as necessidades especificamente teatrais - falta de uma dramaturgia que se moldasse perfeitamente às

1 Estamos chamando de encenação moderna aquilo que $\mathrm{Pa}$ vis denominou encenação clássica, isto é, "uma representação feita sob a perspectiva de um sistema de sentido, controlado por um encenador ou por um coletivo. É uma noção abstrata e teórica, não concreta e empírica. É a regulagem do teatro para as necessidades do palco e do público. A encenação coloca o teatro em prática, porém de acordo com um sistema implícito de organização e sentido" (PAVIS, 2010, p.3).
} 
inquietudes sociais, temáticas e estéticas dos grupos de teatro de então, ou ainda, a busca de uma relação mais participativa com o público - tudo isso é invocado para justificar o aparecimento deste novo modo de criação (SILVA, 2008, p.28).

Conforme observamos na análise de Silva (2008), a criação coletiva estaria assentada no contexto da contracultura e responderia a seu ativismo político com base em comportamentos e atitudes que negavam o individualismo e o consumismo da sociedade burguesa, propondo, por sua vez, um projeto criativo mais comunitário e libertário. Por outro lado, os grupos sentiam necessidade de uma dramaturgia que fosse capaz de expressar suas questões e seus anseios relacionados às temáticas emergentes nos anos 60 e, ao mesmo tempo, que tornasse possível uma relação mais participativa do público.

Nesse contexto, a criação coletiva pretendia redimensionar o trabalho do ator que, segundo a literatura especializada (FERNANDES, 2000; NICOLETE 2005; SILVA, 2008; TROTTA, 2008), abandonaria o lugar de intérprete e passaria a desempenhar o papel de ator-autor. Essa remodelagem do trabalho do ator e de seu papel no teatro, proposta por alguns coletivos, terminou, entretanto, enfraquecida pela busca de uma formação artística mais individualizada e pela emergência da "era do encenador" no Brasil dos anos 80 , conforme salientou Silvia Fernandes (2010). A prática de um teatro de grupo passou a ser substituída pela execução de projetos temporários comandados pelos encenadores. Essa colisão ou entrelaçamento de uma criação coletivizada com a determinação de funções artísticas específicas para cada envolvido geraria, posteriormente, o que chamamos de processo colaborativo.
O processo colaborativo se desenvolveu no Brasil da segunda metade da década de 1990 , sobretudo a partir da retomada do movimento de teatro de grupo na cena paulistana. Esse retorno enquanto prática coletiva e teatro de pesquisa (em contraponto à hegemonia do encenador na década anterior) foi aos poucos ganhando expressiva dimensão nacional. O processo colaborativo é metodologia de criação na qual "todos os integrantes, a partir de suas funções artísticas específicas, têm igual espaço propositivo, produzindo uma obra cuja autoria é compartilhada por todos" (SILVA, 2008, p.57). Nesse sentido, poderíamos dizer que no processo de criação cênica informado já existe um longo trabalho de crítica em exercício, gerando edições, exclusões, recortes etc.

Como marca de um fazer em processo, o colaborativo pressupõe que até no encontro com o espectador o espetáculo ainda estará sofrendo modificações, isto é, sua natureza é a de obra aberta. O pesquisador Renato Cohen a partir da performance como linguagem artística vai utilizar a expressão work in progress para definir a forma artística resultante de trabalhos em que prevalece uma estética processual. Para o autor, "poderíamos traduzir por 'trabalho em processo', procedimento este que tem por matriz a noção de processo, feitura, iteratividade, retroalimentação, distinguindo-se de outros procedimentos que partem de apreensões apriorísticas, de variáveis fechadas ou de sistemas não iterativos (COHEN, 2004, p.19). Dessa forma, a natureza da crítica também se altera, sendo convidada a operar de forma mais mutável e instável, abarcando uma "natureza gerativa para se evitar a cristalização" (COHEN, 2004, p.30) no exercício de análise dos espetáculos, conforme salientou Patrice Pavis (2010, p.35) sobre o que seria então o objeto da crítica: "estamos ainda diante de um objeto estético estável, 
apreensível, descritível? (...) ou diante de obras que se desmancham no ar, reduzidas apenas à experiência estética do espectador?".

Também nos anos 60 , a virada performativa em sua dimensão experimental teria desestabilizado os cânones do fazer teatral, pois atacava alguns dos "fundamentos mais importantes do sistema estético então vigente e que alcançam desde a discussão sobre o que se chamava "carpintaria" do texto teatral até o trabalho do ator e do encenador, levados a novas configurações" (ABREU, 2016). A arte da performance criou fissuras nas estruturas mais clássicas da encenação deslocando, por exemplo, o corpo para o epicentro da cena, o que alterou o estatuto da dramaturgia teatral, além da tensão manifesta entre representação e apresentação, ficção e realidade, personagem e persona, ator-intérprete e performer, espectador e participante.

Se, entretanto, num primeiro momento, a performance parecia negar o teatro, logo depois acabou sendo incorporada pela própria teoria da área: teatro pós-dramático (Lehmann), teatro performativo (Féral), teatro energético (Lyotard), teatros do real (Saison), práticas cênicas liminares (Caballero), teatralidades dissidentes (Sanchez), representação emancipada (Bernard Dort) etc. Segundo Bident (2016), esse terreno expandido alterou o espaço de sua ocorrência, social e artística, antes delimitado ao palco ou ao edifício, confirmando assim "o caráter ilimitado do campo da representação" (BIDENT, 2016, p.52).

O conceito de campo expandido é proveniente dos estudos da crítica norte-americana Rosalind Krauss, que em seu o texto "A escultura no campo ampliado" (publicado originalmente em 1979) apontava para o surgimento de novas formas de produção da escultura, além dos cânones e suportes es- tabelecidos, gerando, assim, uma ampliação desse campo. $\mathrm{O}$ alargamento das fronteiras e uma certa impossibilidade de delimitação mais rígida dos objetos, devido à multiplicidade de combinações entre as distintas linguagens artísticas, acarretaram a criação de obras híbridas e transdisciplinares.

No caso do teatro e da crítica, tais expansividades criaram deslocamentos e tensões entre o que seria produto e processo artístico, bem como na leitura das obras, tanto por parte dos espectadores como dos críticos. A prioridade passa, assim, a ser menos a definição e a significação fechada das obras, ampliando-se para uma experiência aberta e inconclusa no contato com elas. Em vez de uma apreensão consciente dos sentidos e formas presentes numa encenação, passaríamos para uma análise fragmentada e ancorada em rastros de memória num deslocamento que, segundo Lehmann (2007, p.146), seria de uma "poética da compreensão para uma poética da atenção". Dessa forma, o trabalho da crítica é também posto em cheque em função do questionamento do oficio baseado na objetividade do discurso ou do juízo e, por outro lado, na unidade do sentido atribuído a produção ou ao objeto teatral. $O$ crítico se sente desafiado pela multiplicidade de ideais e de perspectivas que nos revela o cenário teatral recente pois, em algumas de suas produções, as ideias modernas de obra e de autoria, baseadas na autonomia do sistema de signos teatrais, não são mais capazes de expressar ou explicar as coordenadas de sua relação com a recepção do espectador, dessa forma expandindo as possibilidades de leitura das cenas, e, desde então, os espectadores são convocados a um jogo de coautoria e presença mais efetiva nos trabalhos. 


\section{Parte 1}

Da resistência crítica na cena contemporânea

No caso das artes cênicas, a noção de campo expandido está relacionada às inúmeras práticas heterogêneas que combinadas revelam o desejo e o interesse de se "criar uma rede, uma espécie de network em que, talvez, em certo momento se faça um workshop. Em outro momento pode ser um seminário, e se conseguiria juntar dinheiro para montar uma peça" (LEHMANN, 2003, p.14). Durante um largo tempo, entretanto, a crítica teatral jornalística não conseguiu, por algum motivo, acompanhar as profundas transformações que aconteciam na cena, deixando, assim, um terreno em aberto, que terminou sendo apropriado por uma prática agora realizada no interior dos grupos, com a parceria de outros olhares externos (filósofos, historiadores etc.) como interlocutores privilegiados.

Vale lembrar que nos anos 60 , algumas produções de grupos, como Arena e CPC, também contaram com a presença de cientistas sociais, historiadores, intelectuais e artistas com os quais mantinham relações específicas visando os processos de criação em curso. Contavam, também, com representantes de movimentos sociais e sindicatos na construção de espetáculos-relâmpago. Em contexto distinto, o que vemos hoje é a possibilidade de inserção do crítico na sala de ensaio, atuando como uma espécie de dramaturg, isto é, um provocador de processos de criação, o que incide na autoria final do trabalho em sua dimensão compartilhada.

Daí ser possível verificar a presença de princípios e procedimentos ancorados tanto numa ideia de trabalho coletivo como de campo expandido nas atuais práticas brasileiras de crítica teatral. Nesse sentido, dife- rente da crítica teatral moderna, o exercício não está mais circunscrito apenas à escrita de textos e ensaios, mas também se vincula a atividades como curadoria, mediação, historiografia, interlocução em processos de formação e criação, além da pesquisa. Justamente por esse atual perfil multifacetado do crítico - cuja presença no campo teatral não está mais limitada ao comentário sobre os espetáculos, entendidos como produtos finais do trabalho dos artistas, grupos e demais coletivos, nem se reduz à escrita de textos e ensaios publicados em veículos específicos -, podemos perceber uma forma diferente de relação entre a crítica e a cena implicadas em diálogos coletivos e experimentando significativas expansões de seus territórios.

Nesse sentido, contrariamente aos estudos de Tania Brandão (2018) e Patrice Pavis (2010), que insistem na tese de um declínio do trabalho do crítico, principalmente após a migração da crítica dos jornais impressos para as plataformas digitais, consideramos que o processo é de redefinição, multiplicação e ampliação do ofício, do campo e do exercício. Por outro lado, conforme observou Henrique Rochelle Meneghini, em seus estudos sobre crítica e dança na contemporaneidade, essa nova configuração tem levado à diluição de uma identidade da crítica devido à dificuldade na delimitação da competência para o ofício, da forma do exercício e de seu território de atuação:

Nota-se também, crescentemente, uma
atividade de publicação virtual em que
autores que não teriam o espaço nos
veículos gerais de circulação impressa
podem publicar seus textos. Essa nova
atividade, sua proliferação e o aumento
do interesse por ela revelam que, ain-
da que aparentemente a crítica tenha
encerrado um ciclo, um outro ciclo dá
seus primeiros passos, com a produção
de textos que se agarram a um enten-
dimento da crítica que não é necessa- 
riamente sequencial: ele não representa obrigatoriamente uma continuidade, mas identifica um desejo reavivado por esse tipo de reflexão. A crítica não é uma. Sua reflexão teórica é variada a abrangente, apoiada em sistemas diversos e distintos de atribuição de sentido e de organização metodológica, resultando na produção de textos que também se mostram de ordens várias. Nessa multiplicidade, parece que a crítica não se define, ou que suas definições não se concretizam, e muitas vezes é difícil determinar o que faz de um texto um texto de crítica, o que faz de um profissional um crítico, a quem a crítica se dirige, e para que a crítica serve (MENEGHINI, 2017, p.75).

Podemos observar que a mudança de veículo e de espaço ocupado pela crítica acaba interferindo na forma do ofício e na maneira do exercício. A crítica nos jornais foi-se reduzindo à dimensão valorativa dos espetáculos, à apreciação deste ou daquele desempenho em cena, deixando de lado um maior exercício de análise e argumentação tanto estética como sociológica dos trabaIhos, o que gerou significativa distância da classe artística que, por sua vez, passou a encarar o crítico mais como um inimigo do que um interlocutor ou um "espectador especializado". O encolhimento do espaço no jornal também interferiu nas possibilidades de uma especulação estética mais aprofundada por parte do crítico, que se viu obrigado a emitir juízos e comentários superficiais sobre a produção artística. Outro fator preocupante foi a consolidação de um leitorespectador que se tornou um consumidor da obra teatral e não mais um potencial pensador e colaborador dos sentidos de uma obra colocados em jogo. Assim um "crítico alfandegário" (COELHO, 2010) tenta resistir à ameaça constante de sua função ser domesticada numa sociedade do consumo e do espetáculo.

Nesse sentido, conforme observou na revista eletrônica Questão de Crítica (RJ) Daniele Avila Small (2008), teríamos duas críticas de naturezas diferentes: a crítica-polícia e a crítica-política. Enquanto a primeira trabalha a partir da adjetivação dos es-petáculos e a manutenção de discursos estéticos, a segunda, por outro lado, buscaria contribuir na construção de novos sentidos, de novas configurações criativas e leituras das obras. Se a crítica-polícia se centra na afirmação categórica, a crítica-política indaga e promove outras possibilidades de discursividade para a cena, não querendo exercer um domínio arbitrário sobre os sentidos existentes nos espetáculos. Desse modo, agindo em consonância com as novas formas do teatro contemporâneo, segundo comentou Kil Abreu (2016), em Crítica teatral: da organicidade à deriva, caminhamos de um campo cênico estruturado rumo a uma errância criativa.

A partir dos anos 90, temos uma reatualização da prática teatral como exercício coletivo devido à profusão de processos colaborativos e à diluição do criador solitário e autônomo; assim, os laços entre programas cênicos e programas críticos não se rompem, pois nessa diversidade de propostas numa "torre de Babel de formas da experimentação teatral contemporânea" (ABREU, 2016) cabe ao crítico a desafiante e necessária tarefa de historicizar não somente sua época como também sua atividade crítica. Uma equação nada simples pelo fato de precisar se alinhar com novos e outros métodos de análise dos espetáculos e, mais, lidar com a adesão ou o desconhecimento das plateias. Um trabalho que exige equilíbrio entre uma não aceitação rápida ou acrítica das novas tendências que despontam e a realização de uma atividade de tradução e mediação dessas novas proposições teatrais para um diálogo com os espectadores.

O trabalho do crítico passa então por 
uma redefinição e recuo reflexivo, diferente da narrativa de sua dissolução frente aos impasses de uma cena contemporânea. $O$ problema, portanto, não é a decadência do ofício crítico hoje, mas sua redefinição em torno das mudanças provocadas pela ampliação da produção e pela diversidade de sua circulação, além da dificuldade em delimitar os diferentes perfis do espectador teatral contemporâneo. O território expandido de atuação do crítico compreende a luta pelo sentido do teatro e de seu lugar no mundo, e, menos que uma superação da crítica moderna ou de seus limites cognitivos, o que vemos hoje é o aumento da complexidade do exercício crítico em função da sobrevivência das formas antigas entrelaçadas às mais recentes.

Sendo assim, de qual crítica estamos falando então? De que teatro estamos falando? Diante de uma visível horizontalidade das práticas artísticas e teóricas, da presença cada vez mais numerosa de artistas nas universidades, é possível problematizar uma separação mais rígida entre os dizeres e os saberes referentes às artes cênicas? Que tipo de relação com o público emerge dessa situação em que, a princípio, o crítico deixaria de ser seu "representante legal", passando a constituir uma voz presente na conversa pública? Do crítico solitário estaríamos então caminhando para um crítico participativo? $\mathrm{O}$ que ganham e o que perdem as artes cênicas nessa aposta contemporânea?

No cenário atual da crítica não existiria mais parâmetros objetivos para o julgamento do crítico e nem para a credencial exigida por seu tipo de exercício, valendo muito mais a força criativa e a sensibilidade, bem como sua capacidade imaginativa e ensaística (SMALL, 2015). Estaríamos diante de um cenário no qual a figura do crítico especializado, dotado de habilidades técni- cas que faziam ou fazem dele autoridade no assunto, parece não satisfazer mais à demanda contemporânea, que passaria, por outro lado, a valorizar as dimensões éticas ou posicionamentos políticos presentes em seus julgamentos. Não estaríamos diante de uma outra forma de cumplicidade, na qual, o pacto entre a prática teatral e a crítica deixa de estar fundado num discursivo exclusivamente poético e ou estético para gravitar em torno da aliança política? Neste sentido, o exercício crítico não buscaria mais oferecer apenas a sua opinião balizada e orientar esteticamente o gosto do público, mas promover ou fazer a gestão de um espaço "comum" entre seu saber, o do criador e o do espectador, num jogo caleidoscópico de perspectivas.

No interior do debate sobre o fazer crítico contemporâneo em campo expandido e como exercício coletivo tem sido considerada importante a contribuição de Daniele Ávila Small (2015), sobretudo sua aposta na formação do que denomina um "crítico ignorante", pois despojado de um saber predefinido, e, assim, disposto a ver o fenômeno cênico com lentes e referências mais livres e capazes de tatear, arriscar, supor e sugerir possíveis e criativos desdobramentos discursivos. Tratar-se-ia de escapar do exercício enquanto agência do mercado teatral ou de diversão que visaria prestar um serviço ao consumidor: o de referendar a qualidade do produto ofertado. O crítico ignorante teria por objetivo, segundo a autora, "apenas exercer a liberdade de dialogar com as obras, interpretá-las, conversar com a sensibilidade daqueles que partilham da admiração, da curiosidade ou da inquietação por estas obras" (SMALL, 2015, p.103-104).

Essas parecem ser as premissas do crítico na atualidade, constituindo a prática de uma política que "elabora estratégias de embaralhamento dos saberes e dizeres so- 
bre teatro" (SMALL, 2015, p.12) e que, para isso, entra em disputa com uma crítica canônica e mais institucionalizada. Tal disputa pode ser verificada quando estudamos a tradição crítica do teatro brasileiro no século passado, nosso próximo tópico neste artigo.

\section{Parte II}

\section{Uma possível trajetória da} crítica teatral brasileira

Como veremos ao longo deste artigo, a história do teatro brasileiro está diretamente relacionada à história da crítica e parece deslizar ora por uma crítica-polícia, ora por uma crítica-política. O crítico do século XIX no Brasil surge do "homem das letras" que, em meio a outras ocupações, exerceu também nas páginas de revistas e jornais a função crítica, especialmente enquanto cronista teatral. Machado de Assis, José de Alencar, José Veríssimo, Artur Azevedo, João do Rio, Lima Barreto, entre outros escritores, contribuíram para a formação de um pensamento sobre o teatro no Brasil e, em suas colunas periódicas ou artigos, discutiram os caminhos e as dificuldades, os impasses e as saídas para a constituição de um "teatro nacional". Dessa maneira, militaram pela "elevação" da produção local e do gosto público, pela redefinição do pacto entre teatro, Estado e sociedade no período que vai de meados do século XIX às três primeiras décadas do século $X X$.

A tarefa do crítico era dupla, pois defendia a "nacionalização" da produção teatral e, ao mesmo tempo, definia critérios pelos quais ela deveria ser realizada, conforme a norma hierárquica dos gêneros vigentes na época. Interessados em elevar dramaticamente o palco nacional, considerado decadente em virtude do sucesso do teatro li- geiro, ${ }^{2}$ valorizavam um teatro mais literário (enfoque na dramaturgia) e de inspiração europeia. Sendo assim, a crítica teatral do começo do século XX assumia caráter normativo e propositivo, posto que baseada num diagnóstico dos males que impediam a formação de um teatro nacional, procurava definir o percurso a ser seguido para sua atualização, conforme o quadro da produção europeia. Num tom professoral, esse "crítico improvisado" (BRANDÃO, 2018) e polemista, fomentado pelo advento da imprensa, censurava o gosto médio do públi$\mathrm{co}$, as escolhas dos empresários, os autores do teatro de revista, ao mesmo tempo que pretendia fazer do teatro um caminho para implementação junto à sociedade do projeto civilizatório almejado por intelectuais e escritores (BRANDÃO, 2018).

Conforme salienta Tania Brandão, a estrutura do texto crítico obedecia à influência francesa, cujo resumé apresentava um relato da trama e abria assim uma possibilidade de análise dos espetáculos. Isso significava que a avaliação do espetáculo se dava a partir da análise literária, e a cena, propriamente dita, recebia um exame rápido e só mencionado no final do texto.

Do ponto de vista da autora, o problema dessa crítica parece residir na marginalização da cena em benefício do texto, gesto que a distanciava da "crítica moderna". Entretanto, podemos perceber que, para além dessa questão moderna, o debate instaurado pelos "críticos improvisados" estaria na disputa entre as distintas propostas de teatro nacional, defendidas pela imprensa naquele contexto. Debate que compreende também as crônicas teatrais de Antônio Alcântara

\footnotetext{
2 A expressão "teatro ligeiro" ou gêneros ligeiros começou a ser utilizada pela crítica jornalística a partir da segunda metade do século XIX para referir-se aos espetáculos de revistas, burletas, vaudevilles e mági-cas. Em oposição ao chamado teatro sério, tais produções eram consideradas criações pouco elaboradas e simplificadas, isto é, sem propósitos artísticos mais elevados.
} 
Machado publicadas, a partir de 1923, no Jornal do Commercio. O autor tem sido visto pela literatura especializada (RAMOS, 1994; LARA, 1987) como um dos primeiros modernistas da cena nacional, e sua atividade crítica dividida em dois momentos: na primeira fase teria defendido uma "saída" dramática para a suposta "decadência" do teatro, partindo de formas e ideias europeias, enquanto, na segunda fase, teria privilegiado em sua proposta de atualização ou "modernização" da produção local o "brasileirismo" que, segundo alegou, poderia ser encontrado no circo, na revista, nas burletas, ou seja, nos gêneros tidos como populares.

O teatro bagunça foi a denominação atribuída por Alcântara Machado à mistura que surgiria do aproveitamento das manifestações populares "onde o povinho se reúne e fala os desejos e os sentimentos que tem" (MACHADO, 2009, p.375). O exercício crítico passa então a ser pela nacionalização dos elencos, contra as influências estrangeiras e, de forma ousada, também se colocando contrário a certa tradição crítica que condenava as pateadas e outras livres manifestações do público quando não gostava dos espetáculos apresentados ou deles discordava. Antônio Alcântara Machado, além de críticas, escreveu manifestos em prol da renovação do teatro brasileiro. Os princípios norteadores de seu programa crítico estavam assentados na ideia de que, nas expressões de vida do povo, o teatro brasileiro encontraria as bases de sua forma e formação nacional, os materiais a explorar na cena, unindo música e dança, como já faziam o teatro de revista, as comédias populares e as cenas da vida cultural cotidiana.

Segundo Ana Bernstein (2005) e Tania Brandão (2010), foi nos anos 40 que a ideia de renovação teatral pôde desdobrar-se num projeto crítico articulado ao palco nacional em virtude das mudanças mais am- plas sofridas pelo teatro brasileiro. Momento decisivo para a afirmação de uma crítica especializada com formação universitária no âmbito da primeira geração da crítica teatral moderna no Brasil, conforme observamos na trajetória da obra de um de seus principais expoentes, Décio de Almeida Prado que, segundo Ana Bernstein, pode ser considerado modelo do "crítico atento e cúmplice" (BERNSTEIN, 2005) dos rumos da modernização do teatro brasileiro.

Mais do que crítico, Décio foi um teórico que contribuiu no Brasil para a compreensão do fenômeno da encenação que já estava em pleno curso na Europa desde o final do século XIX. Suas críticas foram reunidas $e$ publicadas em três livros: Apresentação do teatro moderno brasileiro (1956), Teatro em progresso (1964) e Exercício findo - crítica teatral (1987), além de outros ensaios sobre a história do teatro brasileiro. Escrevendo durante, pelo menos, 22 anos para o jornal O Estado de São Paulo, o crítico se mostrou empenhado na defesa do teatro moderno entre nós, pautando seu exercício num determinado programa crítico que defendia a maior qualidade dos espetáculos a ser obtida por intermédio do encenador, além da inclusão de outros gêneros para além da predominância da comédia, e, como um representante de sua geração de críticos, assinalava a importância do teatro como arte e não apenas diversão ligeira (PRADO, 1987, p.23).

De acordo com Ana Bernstein, a produção de Décio vai assinalar a passagem da crítica-crônica e social que vinha do século XIX para uma nova crítica como discussão estética dos elementos do espetáculo e defesa da profissionalização dos artistas. Entretanto, essa passagem compreendeu distintos momentos do exercício critico que, grosso modo, pode ser dividida em três períodos: os anos de formação, quando o crítico 
começa a escrever para a revista Clima; os anos de consolidação, decorrente do amadurecimento de suas ideias; e os anos de transformação, marcados pelo exercício de revisão de seu trabalho (BERNSTEIN, 2005, p.26). Décio vai abandonar o ofício de crítico em 1968, tendo como causas o agravamento da censura às artes em pleno regime militar e sua dificuldade de acompanhar os novos rumos da cena teatral. A sua visão moderna do oficio e do objeto abarcaria quatro dimensões, a saber: a crítica filosófica, que acentua a discussão estética da obra de arte; a crítica literária, que se aproxima da crônica; a crítica didática, de caráter pedagógico; e a crítica jornalística, que tem como principal objeto a informação (GARCIA, 2000, p. 93), mas, essas distintas facetas ou camadas da escrita e da reflexão crítica estavam comprometidas com seu projeto mais amplo de teatro moderno brasileiro.

Devemos observar que a plataforma crítica do mestre paulista é justificada como um desejo coletivo, isto é, em nome de uma geração. Esse consenso em torno de um determinado projeto crítico moderno do teatro brasileiro, proposto pelo autor em comum acordo com um grupo particular, foi todavia questionado por um de seus ex-alunos, Miroel Silveira. Crítico, tradutor, diretor e professor, embora compartilhando alguns princípios críticos de seu ex-professor, discordava da exclusividade de um teatro elitista como o do TBC em detrimento das demais produções existentes, como, por exemplo, as atividades amadoras de italianos e outros imigrantes, além de espetáculos de teatro de revista ou circo-teatro, que eram considerados precários pela intelligentsia da época.

Em A outra crítica, Miroel Silveira (1976) salientou os fatores econômicos determinantes do projeto estético do teatro moderno de seu ex-professor e que, por outro lado, compreendia poucos grupos ou companhias teatrais privilegiadas por mecenas industriais, marginalizando, assim, o repertório e a trajetória de antigos grupos, como a Cia. Eva Todor, que, sem nenhum tipo de apoio, insistiam no fazer teatral na cidade de São Paulo.

Ao contrário da negação ou da reclamada ruptura com o passado teatral em bloco, o crítico reivindica uma linha de continuidade entre tradição e modernidade, principalmente no que se refere aos antigos atores-estrelas frente aos novos atores formados no curso da EAD ou no bojo dos grupos profissionais capitaneados pelos encenadores europeus. Dessa maneira, o crítico introduz a dimensão sociológica do projeto estético da crítica teatral moderna no Brasil.

Até que ponto, porém, o "crítico especializado" (BERNSTEIN, 2005), surge com a modernização da cena teatral brasileira, escapou dos parâmetros informados anteriormente acerca do "crítico improvisado"? A primeira geração moderna da crítica articulou ou cristalizou em seu discurso renovador alguns dos termos e expressões que já faziam parte do debate, sobretudo as oposições teatro para rir versus teatro sério, teatro comercial versus teatro de arte. Desse modo, podemos observar também as continuidades entre os dois momentos, especialmente o caráter comercial do empreendimento moderno apoiado pelas páginas do jornal. Vale lembrar que o exercício crítico de Décio de Almeida Prado fora decisivo para a consolidação de uma narrativa hegemônica sobre o desenvolvimento moderno do teatro brasileiro que, por sua vez, se desdobrou numa determinada visão histórica de seu passado como um todo.

O afastamento do mestre paulista da crítica periódica coincidiu com a redução do espaço ocupado pelo crítico teatral no jornal, impedindo-o de analisar o espetáculo longamente com o objetivo de educar o gosto do 
público, ficando seu papel reduzido à qualificação breve dos trabalhos visando fornecer uma opinião capaz de orientar sua escolha no mercado de bens culturais. Yan Michalski, que escrevia para o Jornal do Brasil, em texto publicado em 1984, lamentou a perda de espaço para o exercício crítico e o desaparecimento de veículos e de colunas voltados para a cobertura da vida teatral, fatos que, segundo o autor, assinalavam a marginalização do próprio teatro no cenário cultural informado pela imprensa:

A crítica teatral brasileira se vê reduzida a pequenos comentários opinativos sobre espetáculos isolados, ainda tolerados, mais do que valorizados e prestigiados, em alguns raros diários e revistas semanais. Vários órgãos da imprensa que tinham tradição no ramo desapareceram; outros extinguiram suas colunas de crítica; e mesmo os que ainda mantêm tais colunas com alguma regularidade, concedem-Ihes um miniespaço dentro do qual fica quase impossível abrir uma discussão crítica instigante, em alguns casos desestimulam tomadas de posição assumidamente opinativas, ou até determinam ao crítico normas de conduta jornalística que tolhem a sua liberdade de manifestação (MICHALSKI, 1984).

Além do pouco reconhecimento de sua função, as pressões advindas da repressão política e as novas propostas cênicas que despontavam, e que de alguma forma geravam embates e agressões públicas, pareciam contribuir para esse processo de afastamento ou de esgotamento da crítica teatral moderna nos anos 80 . Não é por acaso que, nesse contexto, tenha sido veiculada a tese de uma possível morte da crítica devido a seu recuo forçado ou à sobrevivência de uma prática "moribunda", faltando aí um exercício de autocrítica por parte dos intelectuais modernos.

Sem saída à vista, alguns dos principais críticos optaram pela retirada de cena. Paralelamente, cultivava-se a crítica na universidade, nos programas de pós-graduação em teatro e artes cênicas que, posteriormente, viriam contribuir para a formação e o perfil de outra crítica. Além disso, com a internet surgiram condições para novas plataformas críticas cuja divulgação não dependia mais exclusivamente dos jornais e revistas do circuito comercial mais amplo - num contexto que, segundo observou Daniele Avila Small (2017, p.287), estaria marcado pela abertura proporcionada por uma forma diferente do exercício e do ofício crítico, em sintonia com as mudanças operadas no presente da arte teatral.

\section{Parte III}

Sobre o crítico coletivizado

A história da crítica teatral brasileira no século passado é uma história de indivíduos, isto é, nomes destacados. Os textos publicados nos jornais pelos críticos especializados acabaram por solidificar carreiras exemplares de autores renomados, conforme observou Mariana Barcelos (2016), em Sobre crítica e nomes: "o nome do autor corrobora para a firmação de um pacto implícito - o que é uma crítica de teatro, como se escreve uma crítica, qual a forma legitimada, quem pode escrever". O problema emerge quando a autoridade do crítico se sobrepõe a seu juízo acerca do objeto, afastando-o, muitas vezes, do movimento de atualização da própria cena teatral. Nesse sentido, o distanciamento do crítico do cenário dinâmico da atividade teatral em vez de permitir uma visão mais acurada e livre implicaria falta de diálogo mais consequente com as práticas artísticas vigentes que, por sua vez, se desdobraria em atitudes normativas, paternalistas e catequizantes" (SMALL, 2017, p.281) ao subestimar artistas e espectadores. 
Em consonância com os processos criativos colaborativos e em campos expandidos da cena teatral atual, conforme observou Barcelos (2016), a figura do coletivo agora se insere, portanto, na prática crítica que compreende artistas, críticos e espectadores. Dessa maneira, a crítica contemporânea abriria mão do indivíduo-autor (como única figura de autoridade) para atuar como coletivo-autor. Não haveria mais dessa forma um nome a ser destacado, e o protagonismo seria então de um corpo coletivo de críticos, no qual a crítica (como objeto de estudo e pensamento sobre ela mesma) estaria em primeiro plano e sendo exercida por críticos com diferentes formações, estilos e leituras do que seria o teatro brasileiro. Também não haveria mais um modelo de crítica a ser perseguido ou perpetuado, mas a cada espetáculo um texto diferente poderia ser produzido.

Hoje, o coletivo crítico está inserido em circuitos distintos e plurais de comunicação e de promoção das artes cênicas, particularmente teatrais, organizados em plataformas digitais, e seus atores buscam promover uma reflexão considerada diferenciada e diversa sobre a cena. Vale destacar as seguintes plataformas de crítica teatral em plena atividade: Questão de Crítica (RJ), Horizonte da Cena (MG), Satisfeita Yolanda (PE), Teatro Jornal (SP), Agora Crítica Teatral (RS), Bocas Malditas (PR), Farofa Crítica (RN), Revista Barril (BA), Parágrafo Cerrado (MT) etc.

Dessa perspectiva, o ofício e o exercício críticos estão sendo praticados por diversos agentes e em diferentes frentes de trabalho, sobretudo devido à disseminação da internet como espaço para uma variedade de sites e blogs voltada para o fazer cênico que, por sua vez, costuma explicitar diferentes propostas de crítica em torno de uma concepção mais democrática do exer- cício que se baseia no cuidado, no diálogo; busca apoio na teoria, mas reconhece a importância de se manter relação mais próxima e menos dogmática com a cena teatral, ao menos quanto ao segmento inventivo.

No geral, a produção de críticas no espaço público visa aumentar o interesse das pessoas pelo teatro. Outro fator: diferentes formas de escrita crítica (fora dos padrões impostos pelo jornal ou pelo mercado) são experimentadas, como, por exemplo: acadêmica, jornalística, ensaística, performativa etc. Esse novo caminho que vem sendo trilhado pelos jovens críticos tem por objetivo superar o que eles consideram o "moralismo estético reinante", responsável por uma forma de crítica voltada para discriminar o certo do errado, o que se deve ou não fazer, visaria não à norma mas ao dissenso do quadro hegemônico. Como observou Kil Abreu (2016) em seu texto Crítica teatral: da organicidade à deriva, "A almejada produção do dissenso como tarefa não começa, pois, apenas no confronto com formas carcomidas da crítica teatral. O dissenso só pode começar em nós mesmos".

Contrariamente à perspectiva do dissenso de Kil Abreu, da crítica como uma forma de desordem, Tania Brandão (2018), em A falência da crítica: formas da crítica teatral na história do teatro brasileiro, afirma que atualmente, pela possibilidade que têm os críticos de escrever em estado de razoável independência (sem a pressão dos editores de jornal), suas pautas acabam sendo organizadas de acordo com as tendências cênicas mais hegemônicas, ignorando, assim, outras manifestações teatrais e, dessa forma, refutando o debate mais amplo com a maior parcela do mercado, o que culminaria, segundo a autora, em outro tipo de submissão de seu ofício.

No embate entre as duas posições acima destacadas podemos problematizar al- 
guns pontos: a referida independência do crítico, conforme apontada por Brandão, pode ser questionada quando este, por exemplo, atua profissionalmente em alguns poucos festivais e mostras, precisando, portanto, lidar com diferentes tipos de propostas e espetáculos. Assim, o crítico não precisa mais responder às demandas e aos interesses da pauta jornalística, podendo desenvolver trabalhos alternativos e à margem da publicidade consagrada e majoritária. Nesse sentido, diferente da forma verticalizada do passado, a crítica parece emancipada dos veículos oficiais: "A crítica não é do jornalismo e nem da academia, a crítica é do teatro" (SMALL, 2017, p. 287). Mas, ao se emancipar dos veículos oficiais, em função das plataformas digitais, o crítico não está atrelando seu trabalho aos interesses de grupos de artistas e espectadores em detrimento do grande público? Outro ponto: se os críticos vêm atuando em plataformas digitais com forte acento coletivo ou percebendo a crítica como uma forma de ação coletiva, então, podemos reconhecer nesse cenário uma variedade maior de interesses e uma diversidade de significados sobre a produção teatral no país?

O exercício crítico coletivo ganharia sua forma atual no contato com os artistas e os espectadores mas, diante desse quadro, o que temos são iniciativas isoladas de alguns sites e blogs em sua insistência para que a crítica seja incorporada aos meios de produção teatral. Nos debates e conversas sobre os espetáculos, segundo acentuam os estudos recentes, os espectadores têm muito a contribuir com seu saber crítico e subjetivo sobre aquilo que vivenciaram. $O$ sentido da crítica nasceria de uma "circulação infinita de perspectivas", conforme observou Viveiros de Castro (apud. BIDENT, 2016, p.63), pois, dessa forma, ela estaria em consonância com o teatro entendido em seu campo expandido.

\section{Considerações finais}

Vemos o coletivo crítico de hoje como um agente provocador da cena por meio do diálogo mantido com seu presente (SMALL, 2017, p. 291). Esse diálogo, no entanto, poderia ainda ser enriquecido pelo reconhecimento do passado histórico da crítica de hoje, como, por exemplo, com a crítica mais filosófica de Décio, com as questões sociológicas de Miroel Silveira e até mesmo no interesse de inserção do espectador no debate sobre o teatro, como defendia Alcântara Machado. No passado como no presente, o crítico continua um mediador do fenômeno teatral, ainda que a cada época e contexto específico isso aconteça de forma diferenciada e em diálogo e tensão com as questões de seu tempo.

O crítico hoje se vê cercado por muitas armadilhas: se não se mantiver atento pode tornar-se refém de uma posição altamente acadêmica e distante das produções apresentadas e da vida teatral como um todo; por outro lado, se não se inteirar da multiplicidade de estéticas e teorias, pode ser considerado um analista despreparado e correndo o risco de se manter fiel a determinados tipos de linguagem, de acordo com seu gosto. Há também a possibilidade de omissão de seu gesto crítico caso tenha muita proximidade com parte da classe artística. Fato é que o crítico teatral na atualidade configura elemento essencial numa sociedade marcada pelo consumo e pelo espetáculo, e a perda de sua atividade reflexiva só favorece o aumento dos interesses de uma indústria pseudocultural com seus eventos mercadológicos. O crítico coletivo deseja cada vez mais que as artes cênicas não somente sejam assunto da vida pública e social como também formas de produção de pensamento.

Finalizamos o texto levantando alguns 
questionamentos a abordar adiante: Até que ponto o ofício do crítico exercido coletivamente se diferencia daquele exercido pelo crítico improvisado e especializado? Quais seriam os desafios atuais para a prática da crítica numa sociedade marcadamente tecnológica e atravessada pelo excesso de informação e rarefação do pensamento reflexivo? Se um dos pressupostos do exercício em rede e do oficio coletivo é expandir a discursividade do fazer/pensar o ato cênico, como não abrir mão do gesto crítico que é parte fundamental de seu antigo papel social? Muitas são as questões que ainda solicitam novos estudos.

\section{Referências}

ABREU, Kil. Crítica Teatral: Da organicidade à deriva. Disponível em: http://teatrojor-nal. com.br/2016/05/critica-teatral-da-organicidade-a-deriva/. Acessado em 15/03/2019.

AGORA Crítica Teatral. Disponível em: http:// www.agoracriticateatral.com.br/. Aces-sado em 15/03/2019.

BARCELOS, Mariana. Sobre crítica e nomes. Revista Questão de Crítica, Rio de Ja-neiro, v. IX, n. 67, abril 2016. Disponível em: http://www.questaodecri-tica.com. br/2016/04/sobre-critica-e-nomes/. Acessado em 12/03/2019.

BERNSTEIN, Ana. A Crítica Cúmplice: Décio de Almeida Prado e a formação do teatro brasileiro moderno. São Paulo: Instituto Moreira Salles, 2005.
BIDENT, Christophe. O teatro atravessado. Art Research Journal, v. 3, n. 1, jun.-jul. 2016, p. 50-64. Disponível em: http:// periodicos.ufrn.br/artresearchjournal/article/ view/8504/6807. Acesso em 10/03/2019.

BOCAS Malditas. Disponível em: http:// bocasmalditas.com.br/. Acessado em 15/03/2019.

BORNHEIM, Gerd. Teatro: A Cena Dividida. Porto alegre: L\&PM,1983.

BRANDÃO, Tânia. A Falência da Crítica: formas da crítica teatral na história do teatro brasileiro. Ouvirouver, Uberlândia v. 14, n. 1, jan.-jun. 2018, p. 26-43.

COELHO, Sérgio Silva. O crítico pós-dramático: um alfandegário sem fronteiras. In. FERNANDES, Silvia; GUINSBURG, J. (Org.). O pós-dramático. São Paulo: Perspectiva, 2010, p. 187-197

COHEN, Renato. Work in progress na cena contemporânea: Criação, encenação e re-cepção. São Paulo: Perspectiva, 2004.

DESGRANGES, Flávio; SIMÕES, Giuliana. (Org). $O$ ato do espectador: Perspectivas artísticas e pedagógicas. São Paulo: Hucitec, 2017.

DESGRANGES, Flávio. A pedagogia do espectador. São Paulo: Editora Hucitec, 2003.

FAROFA Crítica. Disponível em: http:// www.farofacritica.com.br/. Acessado em 15/03/2019.

FÉRAL, Josette. Além dos limites: Teoria e prática do teatro. Tradução de Jacó Guins-burg. São Paulo: Perspectiva, 2015. 
FERNANDES, Silvia. Teatralidades contemporâneas. São Paulo: Perspectiva, 2010.

FERNANDES, Silvia. Grupos Teatrais: Anos 70. Campinas: Editora da UNICAMP, 2000.

GARCIA, Clovis. Décio, antes de tudo um crítico teatral. Revista ADUSP, São Paulo, n. 19, Memória, março 2000.

HORIZONTE da Cena. Disponível em: https://www.horizontedacena.com/. Acessado em 15/03/2019.

LARA, Cecília de. De Pirandello a Piolim: Alcântara Machado e o teatro no modernismo. Rio de Janeiro: Instituto Nacional de Artes Cênicas, 1987.

LEHMANN, Hans-Thies. Motivos para desejar uma arte da não-compreensão. Tradução de Stephan Baumgärtel. Revista Urdimento n.08. Florianópolis: Udesc, 2008. p. 141-149.

LEHMANN, Hans-Thies. O Teatro Pós-dramático. Tradução de Pedro Sussekind. São Paulo: Cosac Naify, 2007.

MACHADO, Antonio de Alcântara. Palcos em Foco: Crítica de Espetáculos / Ensaios sobre teatro (1923-1933) /Tentativas no campo da dramaturgia. São Paulo: Editora da Universidade de São Paulo, 2009.

MENEGHINI, Henrique Rochelle. A Crítica Como Metodologia e Análise na Recepção de Dança. Tese de Doutorado. Instituto de Artes da Universidade Estadual de Campi-nas. Campinas, 2017.

MICHALSKI, Yan. O declínio da crítica na imprensa brasileira. Cadernos de Teatro do Tablado, Rio de Janeiro, n. 100, jan.-jun. 1984.
NICOLETE, Adélia. Da Cena ao Texto: dramaturgia em processo colaborativo. Disser-tação (Mestrado). Departamento de Artes Cênicas da Escola de Comunicação e Artes da Universidade de São Paulo. São Paulo, 2005.

PARÁGRAFO Cerrado. Disponível em: https://paragrafocerrado.com.br/. Acessado em 15/03/2019.

PAVIS, Patrice. A Encenação Contemporânea: origens, tendências e perspectivas. Tra-dução de Nanci Fernandes. São Paulo: Perspectiva, 2010.

PRADO, Décio de Almeida. Apresentação do Teatro Brasileiro Moderno. São Paulo: Perspectiva, 1987.

QUESTÃO de Crítica. Disponível em: http:// www.questaodecritica.com.br/. Acessado em 15/03/2019.

RAMOS, Luiz Fernando. Da pateada à apatia: o teatro da bagunça de Alcântara Ma-chado e a crítica de teatro no Brasil. $O$ Percevejo, Rio de Janeiro, v. 2, n.8, 1994, p. 48-51.

REVISTA Barril. Disponível em: https://www. revistabarril.com/. Acessada em 15/03/2019.

SARRAZAC, Jean Pierre. Sobre a Fábula e o Desvio. Rio de Janeiro: Editora 7 Letras, 2017.

SARRAZAC, Jean Pierre. Léxico do Drama Moderno e Contemporâneo. São Paulo: Edi-tora Cosac Naify, 2017.

SATISFEITA YOLANDA. Disponível em: http://www.satisfeitayolanda.com.br/blog/. Acessado em 15/03/2019. 
SILVA, Antônio Araújo da. A Encenação no Coletivo: Desterritorializações da função do diretor no processo colaborativo. Tese de Doutorado. Departamento de Artes Cênicas da Escola de Comunicação e Artes da Universidade de São Paulo. São Paulo, 2008.

SILVEIRA, Miroel. A Outra Crítica. São Paulo: Símbolo, 1976.

SMALL, Daniele Avila. Quanto ao futuro. Notas sobre a relação entre atividade crítica, a condição do espectador e o entusiasmo de participar do debate público sobre as coi-sas do mundo. In: DESGRANGES, Flávio; SIMÕES, Giuliana. (Org.). O ato do especta-dor: perspectivas artísticas e pedagógicas. São Paulo: Hucitec, 2017, p. 280-296.

SMALL, Daniele Avila. O Crítico Ignorante: uma negociação teórica meio complicada. Rio de Janeiro: 7Letras, 2015.

SMALL, Daniele Avila. O Que é, Mais Uma Vez, a Crítica? Disponível em: http://www. questaodecritica.com.br/2008/06/o-que-e-mais-uma-vez-a-critica/. Acesso em 12/04/2019.

TEATRO JORNAL. Disponível em: https://teatrojornal.com.br/. Acessado em 15/03/2019.

TROTTA, Rosyane. A Autoria Coletiva no Processo de Criação Teatral. Tese de Doutorado. Programa de Pós-graduação em Teatro - Universidade Federal do Estado do Rio de Janeiro - Uni-Rio: Rio de Janeiro, 2008. 